\title{
Predictors of High-Risk Behaviors Among Street Children in Zahedan, Southeastern Iran
}

\author{
Hossein Ansari, ${ }^{1}$ Alireza Ansari Moghaddam, ${ }^{1}$ Mahdi Mohammadi,, ${ }^{,}$and Azizollah Arbabisarjou ${ }^{1}$ \\ ${ }^{1}$ Health Promotion Research Center, Zahedan University of Medical Sciences, Zahedan, IR Iran \\ "Corresponding author: Mahdi Mohammadi, Health Promotion Research Center, Zahedan University of Medical Sciences, Zahedan, IR Iran. Tel: +98-9155412155, Fax: \\ +98-5433425375, E-mail: memohammadi@yahoo.com \\ Received 2015 July 12; Revised 2015 October 18; Accepted 2015 November 11.
}

\begin{abstract}
Background: Street children are at risk of various high risk behaviors, but few studies have been performed in this field in Iran and worldwide.

Objectives: This study aimed to assess the prevalence of high risk behaviors and its predictors among street children to design interventions and future research agenda regarding these children in Iran, especially in southeast region.

Patients and Methods: This cross-sectional study was conducted in southeast Iran in 2015. Based on postal map, the city was divided into 5 districts and 216 male street children were selected using snowball sampling. An unstructured questionnaire was provided by integrating 8 previously used questionnaires in different studies with approved validity and reliability and filled through interview and observation. Data was analyzed in Stata.12 software using bivariate and multiple logistic regression by Hosmer-Lemeshow method.

Results: The mean age of subjects was $12.5 \pm 3.2$ years. The lowest mean age of initial use and usually firstly used substance was for cigarette smoking. The prevalence of high risk behaviors was 47.7\% (95\% CI: 44\% - 51\%). In final multiple logistic regression model, separation of parents (OR: 3.8 [95\% CI: 1.86 - 16.2]), peddling activity type (OR: 2.73 [95\% CI: 1.28 - 9.5]) and lower fathers' educational level (OR: 3.83 [95\% CI: 1.86 - 15.4]) significantly increased the prevalence of high-risk behaviors among street children.

Conclusions: The prevalence of high-risk behaviors among street children in southeast Iran is almost high. In this regard, street vendors and children who their parents are illiterate or have been separated are more at risk. Generally, principal organizing these children and family education could decline their problems. However, these actions need intersectoral collaboration in society.
\end{abstract}

Keywords: High-Risk, Dangerous Behavior, Street Children, Iran

\section{Background}

Street children are a population of youngsters that, alone or in groups, perform informal activities such as begging, wandering and other behavior necessary for their own or their family's survival. These children may come back to their home after a day of activities or never return to family at night depending on the circumstances (1). On the other hand, a risky behavior as a behavior or reaction that can potentially harm biological, social, physical and psychological aspects, reaches its peak in youth (2). Therefore, considering health behaviors in adolescents, especially high-risk groups such as street children is very important.

There are tens of millions of street children that most of them live in low- and middle-income countries $(3,4)$, while the researches in this field are scarce worldwide. Studies reported different types of activities among street children, but buying and selling drugs is one of the common behaviors in this population $(5,6)$. Therefore, these children are at risk of many high-risk behaviors, in which their assessment and prevention is a priority in health systems.

Problems including early sexuality, morbidity to sexually transmitted diseases and other infectious diseases, addiction, illicit trade, suicide and physical and mental health problems, are the results of living in streets (7-9). Besides, high-risk behaviors among street children have serious consequences for health system and society in the future. On the other hand, there is an association between cultural capital and high-risk behaviors (10) and as most of these children have low cultural capital, they are at risk of high-risk behaviors more than other youth groups. Thus, recognition of risk factors for high-risk behaviors commitment among street children and their families can lead to identification of a series of principles to address the needs of intervention and consequently decline their problems.

Some studies $(6,11)$ have shown that the prevalence of HIV and HBsAg among street children were $7.6 \%$ and $24 \%$, respectively. Otherwise, as the results of a study in Iran (12), street children have negative results for syphilis, HIV and $\mathrm{HCV}$, but $3 \%$ of them have positive result for HBsAg. An- 
other study conducted in Brazil (13) showed that the prevalence of heavy drug use, tobacco use, alcohol and marijuana among street children are $47.7 \%, 37.9 \%, 22 \%$ and $19.5 \%$, respectively. In this study, $74.2 \%$ of subjects reported that they had used more than one drug in the last year.

There are limited studies about street children in Iran. However, a study conducted in Tehran (14) reported that $36.4 \%, 7.8 \%$ and $3.6 \%$ of children have history of smoking, alcohol consumption and other illicit drugs use, respectively. Another study conducted in Iran reported the rate of substance use among street children as $80 \%$ (15). As we know there is no study about high-risk behaviors among street children in southeast of Iran. However, a study on school adolescents in Zahedan (16) reported the prevalence of physical conflicts, carrying cold weapons and suicide attempts as $38.7 \%, 10.2 \%$ and $14.4 \%$, respectively. This study showed that occurrence of high-risk behavior is related to presence of a drug abuser among family members or friends.

Although there are many street children in Iran and the number of such children is estimated more than 200000 (17), there is little information about health status and prevalence of high-risk behaviors among them, especially in southeastern Iran.

Sistan and Baluchistan province is located in the southeast of Iran and has common borders with Pakistan and Afghanistan. The number of street children is more in both Afghanistan and Pakistan $(5,18)$ and traveling and movement of population between two sides of the border influences this issue in southeast Iran. On the other hand, the number of street children in southeastern Iran is more than other areas in Iran (17). Therefore, study on different aspects of this group, especially in this region, is very important. The present study could be helpful for authorities to improve living standards and health status of street children in Iran, especially in this region.

\section{Objectives}

This study was conducted to estimate the prevalence of high-risk behaviors and its predictors among street children to help health policy masters to design interventions and future research agenda in Iran. Due to lack of data in Iran and Sistan and Baluchistan province, the results of this study can facilitate comparison in future epidemiological studies.

\section{Patients and Methods}

This cross-sectional study was conducted in Zahedan, southeast Iran in 2015. Based on postal map, the city was divided into 5 districts (north, south, center, east and west). About 43 street children were selected using snowball sampling from each district and a total of 216 subjects were studied. The starting point for sampling in each district was the most crowded location, in which street children gathered. The sampling continued until 43 subjects reached in each defined district. "Street children" in this study refers to children aged 10 to 19 years who spend days and/or nights in streets with or without family and subsistence in streets in any way possible.

An unstructured questionnaire was provided by integrating 8 previously used questionnaires in different studies. The validity of questionnaire was approved with at least 0.83 content validity index (CVI) for every question by 10 experts and the reliability was approved by Cronbach's Alpha of 0.76. Three native interviewers (after training on how to complete the questionnaire) collected data. In a pilot study, problems regarding questionnaire and data collection were detected and after modification the study was started. About 6 street children were selected from each district for the pilot study.

At first, the interviewers took consent form children by explaining the goal of study and emphasizing on confidentiality of their outcomes. They conducted their work under comments of supervisor. The questionnaires were filled by interviewers including demographic questions and questions about substance abuse and the cause of becoming street children. Because of the sensitive nature of ethnicity, this variable was not considered in this study. We considered the current status of parents' educational level, parents' job and parents' separation for children who their parents were alive. On the other hand, the three mentioned variables for children with dead parents were considered when they were alive. We believed that these variables could affect children's life at any time and prior to parents' death.

The interviews lasted about 20 minutes and conducted privately and anonymously. Other ethical safeguards such as confidentiality and liberty to interrupt the interview were considered as well. The questionnaires were individually examined to critically analyze internal consistency and any questions with inconsistencies were excluded. In this study "high-risk behavior" was considered as committing at least one of behaviors including substance use from any type (use for at least two months continuously), violence, carrying any weapon, unsafe sexual behaviors, attempt to suicide, inactivity and leaving home or school. In this study, children were not confessed to illegal trade activities, so this behavior was not considered in definition of high-risk behavior.This study was approved by ethical committee of Zahedan University of Medical Sciences. Data was analyzed using Stata.12 software. 


\subsection{Statistical Analysis}

Bivariate analysis was performed using chi-square test to compare factors associated to "high-risk behavior". A multiple logistic regression model was used to measure the strength of association of independent variables in predicting "high-risk behavior" by inserting the same variables used in the bivariate analyses. The Hosmer \& Lemeshow (19) test was used to model estimation and evaluate the goodness-of-fit of logistic regression model. Significance level was defined as $\mathrm{P}<0.05$.

\section{Results}

\subsection{Characteristics}

A total of 216 street children were interviewed in this study. All of them were males. Mean age of subjects was $12.5 \pm 3.2$ years. About $88.9 \%$ of their fathers were self-employed, from whom $21.6 \%$ and $27.6 \%$ were involved in garbage gathering and peddling, respectively. Almost $44.1 \%$ of their fathers were illiterate and $48 \%$ finished only primary education. According to children's report, 93.5\% of their mothers were housewife who were illiterate or had primary education. Regarding living status, 3.7\% of interviewed street children lost their both mother and father and $26 \%$ of them lived with their relatives, grandfather and/or grandmother. Working hours for street children was $7.8 \pm 3.6$ hours per day. In total, $84 \%$ of children worked during the year permanently. Children most frequently reported family conflict [including violence (36\%), parental drug use (33\%), physical abuse (33\%) and neglect (32.1\%)] as their reason for becoming a street child. Most children had lower levels of education or guidance and 23\% had a history of dropout. According to children statement, about $29.2 \%, 18.9 \%, 13.5 \%$ and $22.2 \%$ of them lived by vending (legal and illegal devices and products), rubbish gathering, shoes making or polishing and beggaring or car washing, respectively. The rest were engaged in other activities or a combination of mentioned ones.

\subsection{High Risk Behaviors}

Totally, $47.4 \%$ of children had smoked cigarette in their lifetime. Prevalence of regular smoking was $42.6 \%$ and $2 \%$ of them had a history of alcohol consumption. Table 1 shows the frequency distribution of different substance use among subjects. About $66.7 \%$ of subjects had experienced (at least on time used during past year) or were current user of at least one substance. Cigarette smoking was the firstly used substance in most (Table 1). The average age of children with illiterate parents using substances (at least one substance) was $12.89 \pm 2.1$ years and significantly lower than that of others $(14.09 \pm 3.2)(\mathrm{P}=0.038)$.
Table 1. Frequency Distribution of Different Substance Use Experience or Current Consumption Among Street Children in Zahedan $(\mathrm{N}=216)$

\begin{tabular}{|lc|}
\hline Substance Type & No. $(\%)$ \\
\hline Never used & $72(33.3)$ \\
\hline Only cigarette & $16(7.4)$ \\
\hline Only alcohol & $5(2.3)$ \\
\hline Only nas (Naswar) & $20(9.2)$ \\
\hline Cigarette and pan & $5(2.3)$ \\
\hline Cigarette and nas (Naswar) & $20(9.2)$ \\
\hline Cigarette and opium & $5(2.3)$ \\
\hline Cigarette, hookah and opium & $8(3.7)$ \\
\hline Cigarette, hookah and pan & $10(4.6)$ \\
\hline Cigarette, hookah and nas (Naswar) & $11(5.1)$ \\
\hline Cigarette, opium and nas (Naswar) & $9(4.2)$ \\
\hline Cigarette, opium and pan & $8(3.7)$ \\
\hline Pan and nas (Naswar) & $12(5.5)$ \\
\hline Hookah and nas (Naswar) & $4(1.8)$ \\
\hline Hookah, snuff and nas (Naswar) & $7(3.3)$ \\
\hline Cigarette, opium, hookah, pan and nas(Naswar) & $4(1.8)$ \\
\hline
\end{tabular}

History of substances use among street children who had lost both their parents $(36.4 \%)(\mathrm{P}=0.042)$ or separated parents $(29.1 \%)(P=0.047)$ was significantly higher than other street children. About $43 \%$ reported substance use in at least one of their family members. The prevalence of substances use among children who their father had history of at least one substance use $(30.6 \%)(\mathrm{P}=0.039)$, as well those who had left school $(24.6 \%)(\mathrm{P}=0.048)$ was more than other children.

None of street children had a history of conviction, selfinjuring, unsafe sexual behavior, using shared needle and attempt to suicide. Only 8.3\% reported that they carry knife with themselves and $13.8 \%$ stated that they experienced at least one street fight during last year. Regarding physical activity, all children walked at least two hours a day and there was no sedentary life among them. The nutritional status of children was not acceptable, so that only $38.6 \%$ of them reported eating their meals with their families and others stated to eat their meals as snack. However, as nutritional status of these children is not clear and assessable, nutritional high-risk behavior was not considered.

In total, the prevalence of high risk behaviors was $47.7 \%$ (95\% CI: 44\%-51\%). Table 2 shows the results and related coefficients of bivariate and multiple logistic regression analysis of factors associated with perpetration to high-risk behaviors among street children using Hosmer-Lemeshow method (19).

In bivariate analysis, independent variables, including parents' life status, parents' separation, housing status, child activity type and fathers' education were signif- 
icantly related to doing high-risk behaviors in street children $(P<0.05)$. Variables with less than 0.02 significant level in bivariate analysis entered the multiple model according to Hosmer-Lemeshow method (19). Finally, variables of parents' separation, child activity type and fathers' education remained in the model and were significantly related to doing high-risk behaviors in street children. As a result, separation of parents (OR: 3.8 [95\% CI: $1.86-16.2]$ ), peddling activity type (OR: 2.73 [95\% CI: 1.28 9.5]) and lower fathers' educational level (OR:3.83 [95\% CI: $1.86-15.4]$ ) significantly increased the chance of high-risk behaviors among street children. Children who did not report substance use and having street children in their family members were nearly $12 \%$ and $14 \%$ less likely to perform high-risk behaviors, respectively; however, these results were not statistically significant $(\mathrm{P}<0.05)$.

The Hosmer \& Lemeshow (19) test showed a goodnessof-fit for the model adjustment $(\mathrm{P}=0.31)$, obtaining a sensitivity of $83 \%$ and a specificity of $87 \%$ with a cut-off of $49 \%$.

\section{Discussion}

This study showed that life style of street children in southeast of Iran is not acceptable and the prevalence of high-risk behaviors among them is pretty high. Previous studies $(4,9,11-13,20)$ showed that street children often engage disproportionately in high risk behaviors and have low level of health status and life style. On the other hand, exposure to high risk behaviors and living in poor shelters could lead to disproportionate morbidity due to infectious diseases, psychiatric and physical disorders and retarded growth (2). For appropriate action in this field, studying high-risk behaviors and life status of street children is important.

The prevalence of regular smoking and alcohol consumption were estimated as $42.6 \%$ and $2 \%$, respectively. Both the prevalence of regular smoking and alcohol consumption in this study are lower than a previous study conducted in Sri Lanka (21). On the other hand, the prevalence of smoking among street children in southeast of Iran is more, but alcohol consumption is less than Turkey (6) and capital of Iran (14). Otherwise, children in southeast of Iran often use new substances such as Pan and Snuff (Naas) (about $60 \%$ at present study), which street children of other parts of the country use them rarely. Alcohol use is not the main problem among street children in southeast of Iran, but health authorities should focus to prevent using new natural or synthetic substances. Moreover, educational programs could increase the knowledge and attitude of primary school children about complications of smoking and new prevailing substances in this region as well as being a street child.
In this study, about $8.3 \%$ and $13.8 \%$ of children declared to carry knife and experienced at least one street fight during the last year, respectively. On the other hand, none of them had a history of conviction, self-injuring, unsafe sexual behavior, using shared needle and attempt to suicide. This result is not consistent with previous studies in Tehran (14), Turkey (6) and Nigeria (22). It seems that most of these children in southeastern Iran come to street for working and violence among them is low. About $23 \%$ of subjects had a history of dropout, which was lower than Turkey (6) but more than Tehran (14). Families in this region are populous and parents cannot manage all members of the family. Therefore, children have to work and their parents encourage them to work and make money for the family. However, leaving school could be considered as a high-risk behavior and increasing literacy of parents and warning them is the best way for preventing from dropout. Although, $47.7 \%$ of children have committed at least one risky behavior, which is pretty high, the dominant high-risk behavior was smoking and narcotic substances use. Dealing narcotic substances and illicit materials were common among these children. Therefore, these activities and peddling drug places them at risk of substance abuse resulting in addiction. On the other hand, in this study the prevalence of high-risk behaviors among children engaged in selling was significantly more than other children. It seems that these children sell illicit materials and consequently are at risk of using these substances. However, children making shoe and/or gathering rubbish only aimed to obtain cost of living and have not psychologically tendency to substance use. Besides, fathers of more than $20 \%$ of street children in this study were involved in garbage gathering and retailing (lower-paying jobs). Therefore, there would be an interaction between life status of these children and their parents to more affect life style of street children in southeast of Iran.

In this study, separation of parents significantly increased the chance of high-risk behaviors among street children. Furthermore, children who lost their both parents were more likely to have high-risk behaviors. However, family disruption is common in such setting, which leads to poor family support, inadequate care and supervision. Principle policies for street children should be reviewed regarding their family situations (23) and families play the main role in this context. Moreover, children who had lost their parents or their parents separated should be a priority for the state welfare and charity organizations to be supported in societies.

This study showed that chance of high-risk behavior among children whose fathers were illiterate was two times of those whose fathers had high school educational level and the association between father education and do- 
Table 2. Bivariate and Multiple Exact Logistic Regression Analysis of Factors Associated With Perpetration to high-risk behaviors (Variables With $\mathrm{P}<0.200$ in the Bivariate Analysis Entered Multiple Regression Models Using Hosmer- Lemeshow Method)

\begin{tabular}{|c|c|c|c|c|}
\hline Independent Factors & Total Number at Ris No. (\%) & $\begin{array}{l}\text { Perpetration to High-Risk } \\
\text { Behaviors No. (\%) }\end{array}$ & Bivariate OR ( 95\% CI) & Multivariate OR(95\% CI) \\
\hline Parents' life status & & & & $\mathrm{N} S^{\mathrm{b}}$ \\
\hline Both died & $8(3.7)$ & $6(75)$ & $1.73(1.05,8.3)^{\mathrm{a}}$ & \\
\hline Mother died & $25(11.6)$ & $14(56)$ & $1.24(0.91,7.8)$ & \\
\hline Father died & $42(19.4)$ & $20(47.6)$ & $1.12(0.78,6.8)$ & \\
\hline Both live $^{c}$ & $141(65.3)$ & $63(44.6)$ & 1.00 & \\
\hline Parents' separation & & & & $3.8(1.86,16.2)^{\mathrm{a}}$ \\
\hline Yes & $31(14.3)$ & $23(74.2)$ & $1.86(1.38,9.6)^{\mathrm{a}}$ & 1.00 \\
\hline $\mathrm{No}^{\mathrm{c}}$ & $185(85.7)$ & $80(43.2)$ & 1.00 & \\
\hline Housing status & & & & $N S^{b}$ \\
\hline Live in relatives' house & $57(26.4)$ & $44(77.2)$ & $3.13(1.38,9.6)^{\mathrm{a}}$ & \\
\hline Rented & $109(50.4)$ & $46(42.2)$ & $1.72(0.91,6.3)$ & \\
\hline $\begin{array}{l}\text { Substance use in family } \\
\text { members }\end{array}$ & & & & $N S^{b}$ \\
\hline Yes & $93(43)$ & $45(48.4)$ & $1.12(0.41,9.6)$ & \\
\hline $\mathrm{No}^{\mathrm{c}}$ & $123(57)$ & $58(47.1)$ & 1.00 & \\
\hline $\begin{array}{l}\text { Being street children in the } \\
\text { family }\end{array}$ & & & & $N S^{b}$ \\
\hline Yes & $65(30.1)$ & $33(50.7)$ & $1.14(0.55,11.4)$ & \\
\hline $\mathrm{No}^{\mathrm{d}}$ & $151(69.9)$ & $70(46.3)$ & 1.00 & \\
\hline Father's job ${ }^{c}$ & & & & $N S^{d}$ \\
\hline Scavenger & $40(21.6)$ & $26(65)$ & $1.72(0.99,9.3)$ & \\
\hline Peddle and vending & $51(27.6)$ & $24(47)$ & $1.21(0.87,7.16)$ & \\
\hline Driver & $39(21.1)$ & $19(48.7)$ & $1.24(0.88,8.5)$ & \\
\hline Homs' worker or cleaner & $14(6.5)$ & $10(71.4)$ & $1.64(0.94,10.1)$ & \\
\hline Housewife $^{c}$ & $202(93.5)$ & $93(46)$ & 1.00 & \\
\hline \multicolumn{5}{|l|}{ Child activity type $^{d}$} \\
\hline Peddle and vending & $54(34.8)$ & $44(81.5)$ & $2.34(1.4,11.6)^{\mathrm{a}}$ & $2.73(1.28,9.5)^{\mathrm{a}}$ \\
\hline Rubbish gathering & $35(22.6)$ & $21(60)$ & $1.73(0.99,11.9)$ & $1.83(0.96,15.3)$ \\
\hline Shoes making or polishing & $25(16.1)$ & $11(44)$ & $1.26(0.89,9.8)$ & $1.61(0.91,8.1)$ \\
\hline Beggaring or car washing ${ }^{c}$ & $41(26.5)$ & $15(36.5)$ & 1.00 & 1.00 \\
\hline \multicolumn{5}{|l|}{ Fathers' Education } \\
\hline Illiterate & $95(44.1)$ & $50(52.6)$ & $4.66(2.01,10.68)^{\mathrm{a}}$ & $3.83(1.86,15.4)^{\mathrm{a}}$ \\
\hline Primary education & $104(48.1)$ & $51(49)$ & $4.22(1.67,11.00)^{\mathrm{a}}$ & $2.14(0.84,13.1)$ \\
\hline Guidance or high school ${ }^{\mathrm{c}}$ & $17(7.8)$ & $2(11.7)$ & 1.00 & 1.00 \\
\hline
\end{tabular}

${ }^{\text {a }}$ Significant at $\mathrm{P}<0.05$

${ }^{\mathrm{b}}$ No significant.

${ }^{c}$ Reference group.

'Only children with specified activity and their fathers' job included. 
ing high-risk behavior was significant. This result is consistent with a study in Brazil (13). However, children whose fathers are illiterate are often from families with low social level and have no information about the effects of highrisk behaviors. On the other hand, street children whose parents are educated, but work in street for some reasons, seem to earn money and probably help their families and do not do high-risk behaviors. This issue shows the importance of education and arising public knowledge. Highrisk behaviors have psychological and social origin (10), which is parallel with the results of a previous study in China (24) suggesting that parent-child separation in earlier childhood leads to aggressive behaviors.

Lower age of illicit drug abuse among these children indicates that these groups are more vulnerable to adverse environmental conditions that may result in high prevalence of violence and addiction in societies. Meanwhile, the life pattern of street children make them vulnerable to psychosocial problems, which could result in many complications in the society in the next years. Therefore, authorities should act properly and organize these children. In this regard meeting with parents and supporting children financially could be effective.

A limitation in our study was the sampling method. Due to the nature of study population, it was not possible to use any form of random sampling, which would have increased external validity of results.

\subsection{Conclusion}

The prevalence of high-risk behaviors among street children in southeast of Iran is almost high. In this regard, street vendors and children whose their parents are illiterate or have been separated are more at risk. However, recognition of risk factors about high-risk behaviors in street children and their families can lead to identification of a series of principles to address the needs of intervention to decline their problems.

Although it is important to have insight into street children to help them improve their lives status, but there is no study about this vulnerable group in southeastern Iran. Risk factors specified at present study can be useful in identifying high-risk families (whose children are more likely to become a street child and perpetrate to risky behaviors) and hence could help setting timely prevention and rehabilitation programs.

Financial support of poor children and their families to finish at least primary education and job trainings could prevent being street children. However, this action needs intersectoral collaboration. State welfare organization can explore and collect theses children, education organization can educate them and health sector could help them regarding physical and mental health promotion. Due to rapid population growth, especially in southeast of Iran and consequently poverty in cities, street children are expected to be increased in southeast of Iran in the near future.

\section{Acknowledgments}

The authors appreciate children and their family who kindly participated in this study.

\section{Footnotes}

Authors' Contribution: Study concept and design: Hossein Ansari and Alireza Ansarimoghadam; analysis and interpretation of data: Mahdi Mohammadi; drafting and critical revision of the manuscript: Azizollah Arbabisajou.

Funding/Support: This work was supported by Zahedan University of Medical Sciences.

\section{References}

1. Goncalves de Moura Y, van der Meer Sanchez Z, Noto AR. Diversity of contexts in drug use among street adolescents. Qual Health Res. 2010;20(9):1241-53. doi: 10.1177/1049732310370967. [PubMed: 20479135].

2. Reyna VF, Rivers SE. Current Theories of Risk and Rational Decision Making. Dev Rev. 2008;28(1):1-11. doi: 10.1016/j.dr.2008.01.002. [PubMed: 19255598].

3. UNICEF Executive Board . Exploitation of working children and street children. USA: UNICEF; 1986.

4. Woan J, Lin J, Auerswald C. The health status of street children and youth in low- and middle-income countries: a systematic review of the literature. J Adolesc Health. 2013;53(3):314-321 e12. doi: 10.1016/j.jadohealth.2013.03.013. [PubMed: 23706729].

5. Ali M, Shahab S, Ushijima H, de Muynck A. Street children in Pakistan: a situational analysis of social conditions and nutritional status. Soc Sci Med. 2004;59(8):1707-17. doi: 10.1016/j.socscimed.2004.01.031. [PubMed: 15279927].

6. Turkmen M, Okyay P, Ata O, Okuyanoglu S. A descriptive study on street children living in a southern city of Turkey. Turk J Pediatr. 2004;46(2):131-6. [PubMed: 15214741]

7. Belfer ML, Rohde LA. Child and adolescent mental health in Latin America and the Caribbean: problems, progress, and policy research. Rev Panam Salud Publica. 2005;18(4-5):359-65. [PubMed: 16354433].

8. de Carvalho FT, Neiva-Silva L, Ramos MC, Evans J, Koller SH, Piccinini CA, et al. Sexual and drug use risk behaviors among children and youth in street circumstances in Porto Alegre, Brazil. AIDS Behav. 2006;10(4 Suppl):57-66. doi: 10.1007/s10461-006-9124-4. [PubMed: 16845605].

9. Towe VL, ul Hasan S, Zafar ST, Sherman SG. Street life and drug risk behaviors associated with exchanging sex among male street children in Lahore, Pakistan. J Adolesc Health. 2009;44(3):222-8. doi: 10.1016/j.jadohealth.2008.09.003. [PubMed: 19237107].

10. Dehghan Dehnavi G, Parsamehr M, Naseri S. Cultural capital and high risk behaviors among youth. Int J High Risk Behav Addict. 2014;3(1):17595. doi: 10.5812/ijhrba.17595. [PubMed: 24971301].

11. Karmacharya D, Yu D, Dixit S, Rajbhandari R, Subedi B, Shrestha S, et al. A study of the prevalence and risk factors leading to HIV infection among a sample of street children and youth of Kathmandu. AIDS Res Ther. 2012;9(1):25. doi: 10.1186/1742-6405-9-25. [PubMed: 22929124]. 
12. Vahdani P, Hosseini-Moghaddam SM, Gachkar L, Sharafi K. Prevalence of hepatitis B, hepatitis C, human immunodeficiency virus, and syphilis among street children residing in southern Tehran, Iran. Arch Iran Med. 2006;9(2):153-5. [PubMed: 16649359].

13. Moura YG, Sanchez ZM, Opaleye ES, Neiva-Silva L, Koller SH, Noto AR. Drug use among street children and adolescents: what helps?. Cad Saude Publica. 2012;28(7):1371-80. [PubMed: 22729267].

14. Ahmad Khaniha AR, Hakim Shooshtari M, Mohammadian M, Bidaki R, Pourrashidi Boshrabadi A. Familial characteristics of street children in tehran, iran. Iran J Psychiatry Behav Sci. 2014;8(2):86-9. [PubMed: 25053962].

15. Navipour R, Mohebbi MR. Street children and runaway adolescents in Iran. Indian Pediatr. 2004;41(12):1283-4. [PubMed: 15623922].

16. Ansari-Moghaddam A, Bakhshani NM, Hoseinbore M, Shahhraki Sanavi F. High-risk behaviors related to intentional and unintentional harm in adolescents of zahedan, iran. Int J High Risk Behav Addict. 2015;4(1):20328. doi: 10.5812/ijhrba.20328. [PubMed: 25861582].

17. The support Committee for Iranian's street children . Iran has over 200000 street children Available from: http://www. Iranstreetchildren.com.

18. Ali M, de Muynck A. Illness incidence and health seeking behaviour among street children in Rawalpindi and Islamabad, Pakistan-a qual- itative study. Child Care Health Dev. 2005;31(5):525-32. doi:10.1111/j.13652214.2005.00545.x. [PubMed: 16101647].

19. Hosmer DW, Lemeshow S. Applied logistic regression. 2 ed. New York: John Wiley \& Sons; 2001.

20. Auerswald CL, Eyre SL. Youth homelessness in San Francisco: a life cycle approach. Soc Sci Med. 2002;54(10):1497-512. [PubMed: 12061484].

21. Senaratna BC, Wijewardana BV. Risk behaviour of street children in Colombo. Ceylon Med J. 2012;57(3):106-11. doi: 10.4038/cmj.v57i3.4047. [PubMed: 23086025].

22. Olley BO. Social and health behaviors in youth of the streets of Ibadan, Nigeria. Child Abuse Negl. 2006;30(3):271-82. doi: 10.1016/j.chiabu.2005.10.011. [PubMed: 16519940].

23. Lam D, Cheng F. Chinese policy reaction to the problem of street children: An analysis from the perspective of street children. Children and Youth Serv Rev. 2008;30(5):575-84. doi: 10.1016/j.childyouth.2007.11.009.

24. Ge X, Hu TJ, Liu Y, Zhang WW, Yu TT, Wang GF, et al. [Study on the relationship between child abuse, parent-child separation in childhood and the aggressive behavior in adolescence among 1417 junior high school students]. Zhonghua Liu Xing Bing Xue Za Zhi. 2013;34(1):5-9. [PubMed: 23648240]. 